\title{
Surgical Retrieval of Atrial Septal Occluder Device after Late Embolization in Right Ventricle
}

\author{
Soumyadip Saha1 ${ }^{*}$, Tanunita Mondal ${ }^{2}$, Saket Agarwal' ${ }^{1}$, M. A. Geelani ${ }^{1}$ \\ ${ }^{1}$ Department of Cardiothoracic and Vascular Surgery, GB Pant Institute of Post Graduate Medical Education and Research, New \\ Delhi, India \\ ${ }^{2}$ Department of Anaesthesiology and Critical Care, GB Pant Institute of Post Graduate Medical Education and Research, New \\ Delhi, India \\ Email: *soumyadipmedicos03@gmail.com
}

How to cite this paper: Saha, S., Mondal, T., Agarwal, S. and Geelani, M.A. (2018) Surgical Retrieval of Atrial Septal Occluder Device after Late Embolization in Right Ventricle. World Journal of Cardiovascular Surgery, 8, 233-238.

https://doi.org/10.4236/wjcs.2018.812023

Received: November 13, 2018

Accepted: December 18, 2018

Published: December 21, 2018

Copyright (c) 2018 by authors and Scientific Research Publishing Inc. This work is licensed under the Creative Commons Attribution International License (CC BY 4.0).

http://creativecommons.org/licenses/by/4.0/

\begin{abstract}
Atrial septal defect (ASD) is the fourth most common congenital heart disease in the world. It was treated with surgical closure with the help of CPB in the earlier days. Now there are two approaches available, open surgery under $\mathrm{CPB}$ and transcatheter closure. Here we are going to present late complication of transcatheter closure of ASD.
\end{abstract}

\section{Keywords}

ASD, Transcatheter Closure

\section{Introduction}

Atrial septal defects (ASDs) are one of the most common congenital heart defects, with a prevalence estimated to affect 100 of 100,000 live births [1]. Ostium secundum (OS) defect is the most common type of ASD accounting for $75 \%$ of all ASD cases, and 7\% of all congenital cardiac defects [2]. Both surgical and nonsurgical closures of this septal defect are available, provided that specific indications and criteria are met for each procedure. The first transcatheter closure [3] using a double umbrella device in human being was performed in 1976. There are many advantages of transcatheter closure. Transcatheter closure with the Amplatzer ${ }^{\mathrm{TM}}$ septal device occluder has gained popularity in OS-ASD. Embolisation is the commonest reason for surgical intervention among other complications. In this report, we present three cases who underwent successful surgical retrieval of an ASD occluder device embolized to right ventricle, months 
after the procedure.

\section{Case 1}

A $9 \mathrm{yr}$ old girl presented in cardiology OPD with history of insidious onset, gradually progressive palpitation along with frequent upper respiratory tract infection. She was diagnosed as a case of Ostium Secondum Atrial Septal defect (OS-ASD) $(28 \mathrm{~mm})$ with left to right shunt and was undergone ASD closure with Cera ${ }^{\mathrm{R}}$ ASD occluder (LT-ASD-30). During her regular visit to OPD, Chest X Ray (Figure 1), Transthoracic Echocardiographic (TTE) evaluation was performed. It was found that the device embolized in the right ventricular outflow tract (RVOT).Fluoroscopy guided retrieval with $20 \mathrm{~mm}$ snare retrieval forceps was attempted but it was unsuccessful. In RV angiogram (Figure 2) it was seen to be adherent to RV. The patient had no symptoms, such as chest discomfort or

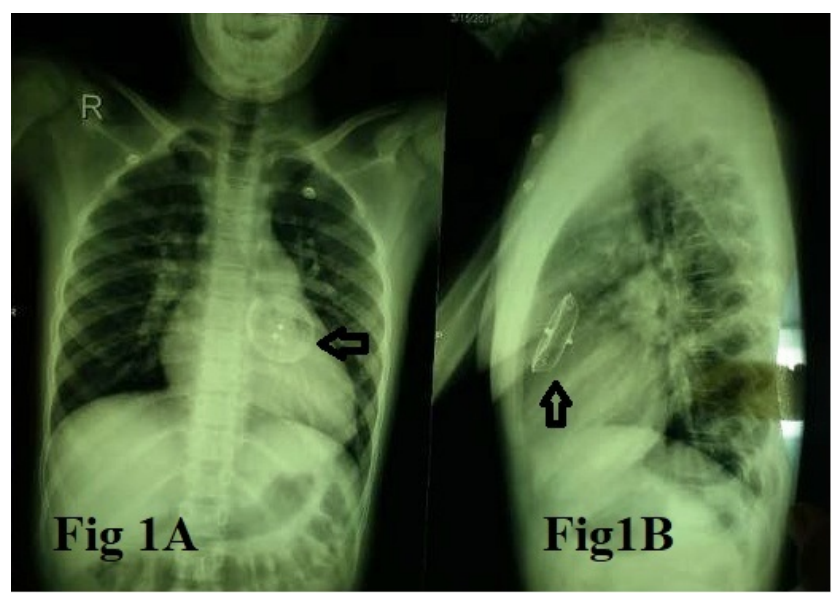

Figure 1. Chest $\mathrm{X}$ ray PA and lateral view showing embolization of the device at RV. The arrows indicate the embolised device.

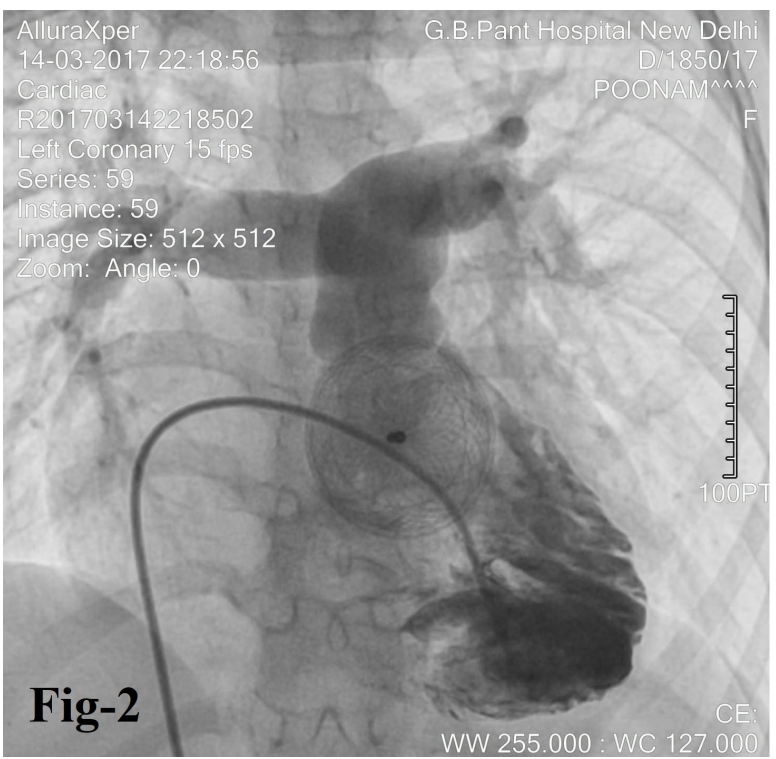

Figure 2. RV angiogram showing embolised ASD occluder device near RVOT. 
dyspnoea, or any haemodynamic instability associated with ASD occluder embolization. Physical examination revealed normal findings. The patient was referred to CTVS OR for management due to the risk of plugging or perforation.

The operation was started under general anesthesia. Informed consent was taken. In supine position median sternotomy was done and pericardial patch was harvested. After systemic heparinisation aortobicaval cannulation and cardiopulmonary bypass was established. Topical ice slush was put over heart. Aortic Cross clamp was applied and aortic root cardioplegia (DelNido $500 \mathrm{ml}$ ) was given. Temperature was drifted to 31 degree celcius. SVC and IVC were snugged. RA was opened via standard atriotomy and the device was found impacted in RVOT. It was retrieved safely (Figure 3(A), Figure 3(B)). ASD was closed with pericardial patch with continuous 5-0 prolene suture. Rewarming was started. RA was closed. Cross clamp was removed after standard deairing and gradually was weaned off from CPB. Protamine was given. Epicardial pacing wire was put over RV. After adequate haemostasis, sternum was closed using stainless steel wire. The total procedure was uneventful. Patient was shifted to ICU on elective mechanical ventilation. The postoperative course was uneventful and the patient was discharged with full recovery.

\section{Case 2}

A 16 years old female patient presented to Cardiology OPD with history of acute onset palpitation and chest pain. She had history of ostium secondum ASD of 20 $\mathrm{mm}$ with left to right shunt. The ASD was closed using Amplatzer ${ }^{\mathrm{TM}}$ ASD occluder system six months back. Physical examination showed atrial fibrillation. Chest Xray PA view (Figure 4) was suggestive of embolization of device and Transthoracic echocardiography revealed embolization of the device in the Right ventricle. Fluroscopy confirmed that the device was embolised in the RV. The patient was referred to CTVS dept for further management. The patient was taken up for surgery immediately after due consent.

\section{Case 3}

A 26 years old male patient presented to Cardiology OPD with history of insidious

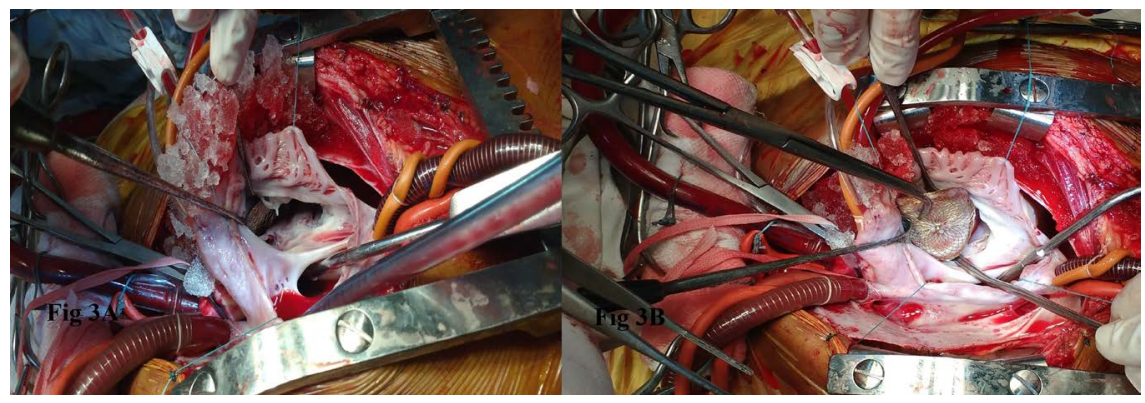

Figure 3. (A) Intraoperative view after retracting the tricuspid valve showing device embolization in right ventricle at outflow tract. (B) Intraoperative trans right at rial view before removal of the device. 


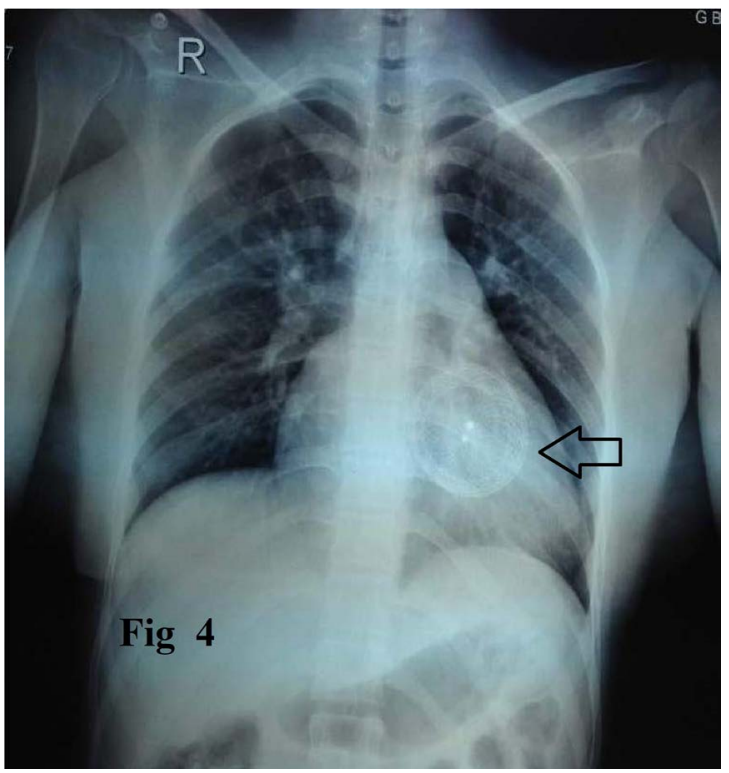

Figure 4. Chest $\mathrm{X}$ ray PA view showing embolosation of device at right ventricle (RV). The arrow indicates the embolised device.

onset palpitation and breathlessness. He had history of ostium secondum ASD $(24 \mathrm{~mm})$ with left to right shunt for which was closed with Lifetec Cera ${ }^{\mathrm{R}}$ ASD occluder system four and half months back. Physical examination showed atrial fibrillation. Chest X ray PA view and Transthoracic echocardiography revealed embolization of the device in the Right ventricle. Fluroscopy confirmed that the device was embolised in the RV. The patient was referred to CTVS dept for further management. The Fluroscopy guided retrieval was not attempted.

\section{Discussion}

There are different types of devices are available for Transcatheter closure of ASD, like Amplatzer Septal Occluder, Figulla Flexible Occlutech Septal Occluder, Gore Helex Septal Occluder, Gore Cardioform Septal Occluder etc. Lifetech Cera is new, less expensive double disk ASD occluder.

There are some of the major sequelae documented in percutaneous device closure like device migration/embolization, cardiac erosion, perforation, arrhythmias, thrombosis, and sepsis etc. The incidence of occluder device embolization after ASD closure [4] is $0.55 \%-1.4 \%$. According to the MAUDE (Manufacturer and User Facility Device Experience) database, 77.2\% case device was retrieved surgically and only $16.7 \%$ was retrieved using percutaneous technique [5]. The device embolization can occur within the first few days as well as few years after the intervention as reported in the literature. Most of the embolization reported in the literature occurred in the recent post operative period, within days of the procedure. In our series, device embolization occurred after 4 months, 6 months and $4 \&$ half months of the procedure.

The reported sites of embolisation include right ventricle, RVOT, pulmonary artery [6], left atrium, LVOT, arch of aorta, descending thoracic aorta, abdomi- 
nal aorta, common iliac artery. In our series device was embolized to right ventricular outflow tract and right ventricle.

The common reasons for the device embolization are very large defect, undersized ASD device, small left atrium to accommodate the device, inadequate margin of ASD and technical issues.

Patients with large ASD ( $>38 \mathrm{~mm}$ ) defects with deficient rims are usually not offered transcatheter closure but are referred for surgical closure at our institution. In our case defect size was $28 \mathrm{~mm}, 24 \mathrm{~mm} 24 \mathrm{~mm}$. Transthoracic echocardiography in all the cases were favourable for device closure. The device mobility after the implantation and the aortic rim narrower than $5 \mathrm{~mm}$ also increase the risk of early and late embolization [7].

Retrieval of the ASD device can be done by both percutaneous and surgical approach. Previous case reports [8] showed percutaneous retrieval was successfully done with Gooseneck snare, En-Snare System, endomyocardial biopsy forceps etc. In our series, device was adherent to right ventricular wall so percutaneous retrieval failed. In one case retrieval was not attempted due to preoperative haemodynamic instability. There was a chance of thrombosis and endothelization of the device in the right ventricular wall, so surgical retrieval of devices were done. ASD was closed with pericardial patch. The endothelialization status of the retrieved device (Figure 5) showed that embolization may have occurred months earlier. Simple Transthoracic Echocardiographic evaluation in the early follow up period can confirm the position of the device.

\section{Analysis}

ASD are mostly closed by device nowadays. The procedure has many advantages with a few complications like we have presented. In early postoperative period the chances of embolization are more. We have presented three cases where all of the patients have embolization of device in the late post operative period.

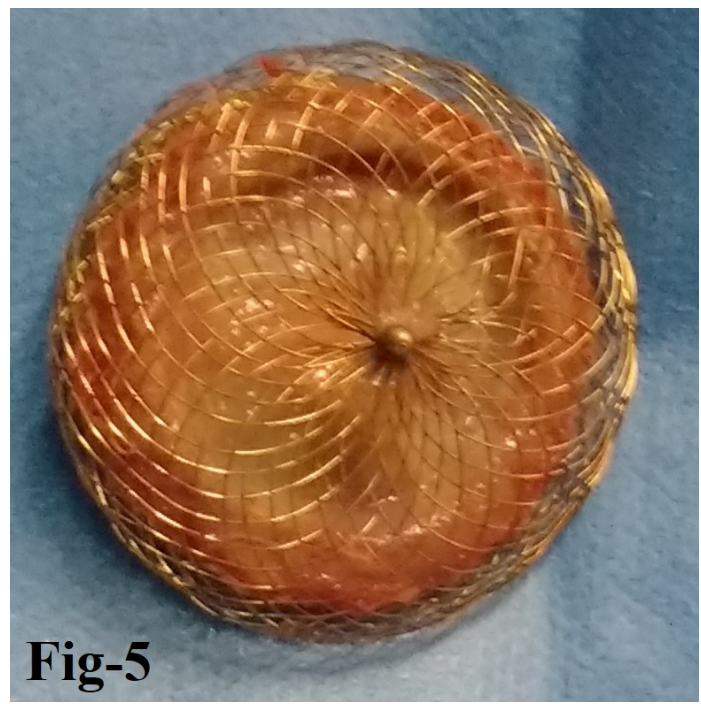

Figure 5. Cera occluder device after removal. 
In early post operative period tranthorasic echocardiographic evaluation carefully can detect this complication.

\section{Conclusion}

Percutaneous closure of ASD is widely performed intervention nowadays. Device closure has many advantages like avoidances of $\mathrm{CPB}$, scar less postoperative pain and reduced hospital stay. There are some procedure related complications like embolization. This emphasizes the need of careful monitoring of patients to avoid complications.

\section{Conflicts of Interest}

There is no conflict of interest.

\section{References}

[1] Bedford, E., Papp, C. and Parkinson, J. (1941) Atrial Septal Defect. British Heart Journal, 3, 37. https://doi.org/10.1136/hrt.3.1.37

[2] Adler, D.H. (2017) Atrial Septal Defect. https://emedicine.medscape.com/article/162914

[3] King, T.D., Thompson, S.L., Steiner, C., et al. (1976) Secundum Atrial Septal Defect. Nonoperative Closure during Cardiac Catheterization. JAMA, 235, 2506-2509. https://doi.org/10.1001/jama.1976.03260490024013

[4] Amanullah, M.M., Siddiqui, M.T., Khan, M.Z. and Atiq, M.A. (2011) Surgical Rescue of Embolized Amplatzer Devices. Journal of Cardiac Surgery, 26, 254-258. https://doi.org/10.1111/j.1540-8191.2011.01249.x

[5] Moore, J., Hegde, S., El-Said, H., et al. (2013) Transcatheter Device Closure of Atrial Septal Defects: A Safety Review. JACC: Cardiovascular Interventions, 6, 433-442. https://doi.org/10.1016/j.jcin.2013.02.005

[6] Lysitsas, D.N., Wrigley, B., Banerjee, P., Glennon, P.E., Parmar, J.M., Shiu, M.F. and Been, M. (2009) Presentation of an Embolised Amplatzer Septal Occluder to the Main Pulmonary Artery 2 Years after Implantation. International Journal of Cardiology, 131, 106-107. https://doi.org/10.1016/j.ijcard.2007.07.072

[7] Sahin, D.Y., Koç M., Cakır, H., Arık, O.Z., Elbasan, Z. and Caylı, M. (2012) A Silent and Late Embolization of Atrial Septal Defect Occluder Device into the Right Pulmonary Artery: A Case Report. Korean Circulation Journal, 42, 781-783. https://doi.org/10.4070/kcj.2012.42.11.781

[8] Huang, T.C., Hsieh, K.S., Lin, C.C., et al. (2008) Clinical Results of Percutaneous Closure of Large Secundum Atrial Septal Defects in Children Using the Amplatzer Septal Occluder. Heart Vessels, 23, 187-192. https://doi.org/10.1007/s00380-007-1028-3 